\title{
Checklist for Theoretical Report in Epidemiological Studies (CRT-EE): explanation and elaboration
}

\author{
I ${ }^{1}$ Breno Augusto Bormann de Souza Filho, ${ }^{2}$ Érika Fernandes Tritany, \\ ${ }^{3}$ Cláudio José Struchiner I
}

Abstract: Introduction: The theory is considered essential to research, however, its value is often underestimated in development and/or reporting in epidemiological studies. Objective: To present a document for the elaboration and explanation of an instrument for theoretical reporting in epidemiological studies.

Methods: A theoretical model was developed, based on the theory of Meaningful Learning and literature review, to list dimensions and variables related to the quality of theoretical reporting. The review was carried out between July 2018 and August 2019, in the databases: Medline, SciELO, LILACS, SCOPUS and Web of Science. There were no restrictions related to the period of publications. The languages used were: Portuguese, English and Spanish. Results: A checklist of 15 points was developed, related to the title (1), abstract (1), introduction (4), methods (4), results (2), discussion (2) and conclusion (1) of the articles; and presents a column for marking the information requested in the article for each point. Explanations about each point of the instrument are presented, including examples, references to studies and justifications.

Conclusion: This document provides guidance for improving theoretical reporting in epidemiological research and facilitates theoretical evaluation and interpretation of studies by reviewers, editors and readers.

> Keywords: models; theoretical; checklist; epidemiologic studies.

\author{
'Escola Nacional de Saúde Pública \\ - ENSP/FIOCRUZ, Rio de Janeiro- \\ RJ, Brazil (brenobormann@ \\ hotmail.com). \\ ORCID: 0000-0002-1700-8688 \\ 2 Instituto de Estudos em Saúde \\ Coletiva - IESC/UFRJ, Rio de \\ Janeiro-RJ, Brazil (erika.tritany@ \\ gmail.com). \\ ORCID: 0000-0002-7099-4800 \\ ${ }^{3}$ Escola Nacional de Saúde Pública \\ - ENSP/FIOCRUZ, Rio de Janeiro- \\ RJ, Brazil (claustru@gmail.com). \\ ORCID: 0000-0003-2114-847X
}




\section{Introduction}

Scientific practice can be characterized as the interpretation of knowledge regarding a time, person, or place acquired through the combination of theory, methodology, and reporting (SOUZA FILHO; STRUCHINER, 2021). Thus, we developed a theoretical model of scientific quality assumptions for epidemiological studies (figure 1), which reveals that epidemiological studies of high scientific quality are only possible when these pillars of knowledge (theory, methodology, and reporting) are of high quality, and there is no hierarchical relationship among them or prioritization of one pillar over the others.

Figure 1. Theoretical model of scientific quality assumptions for epidemiological studies

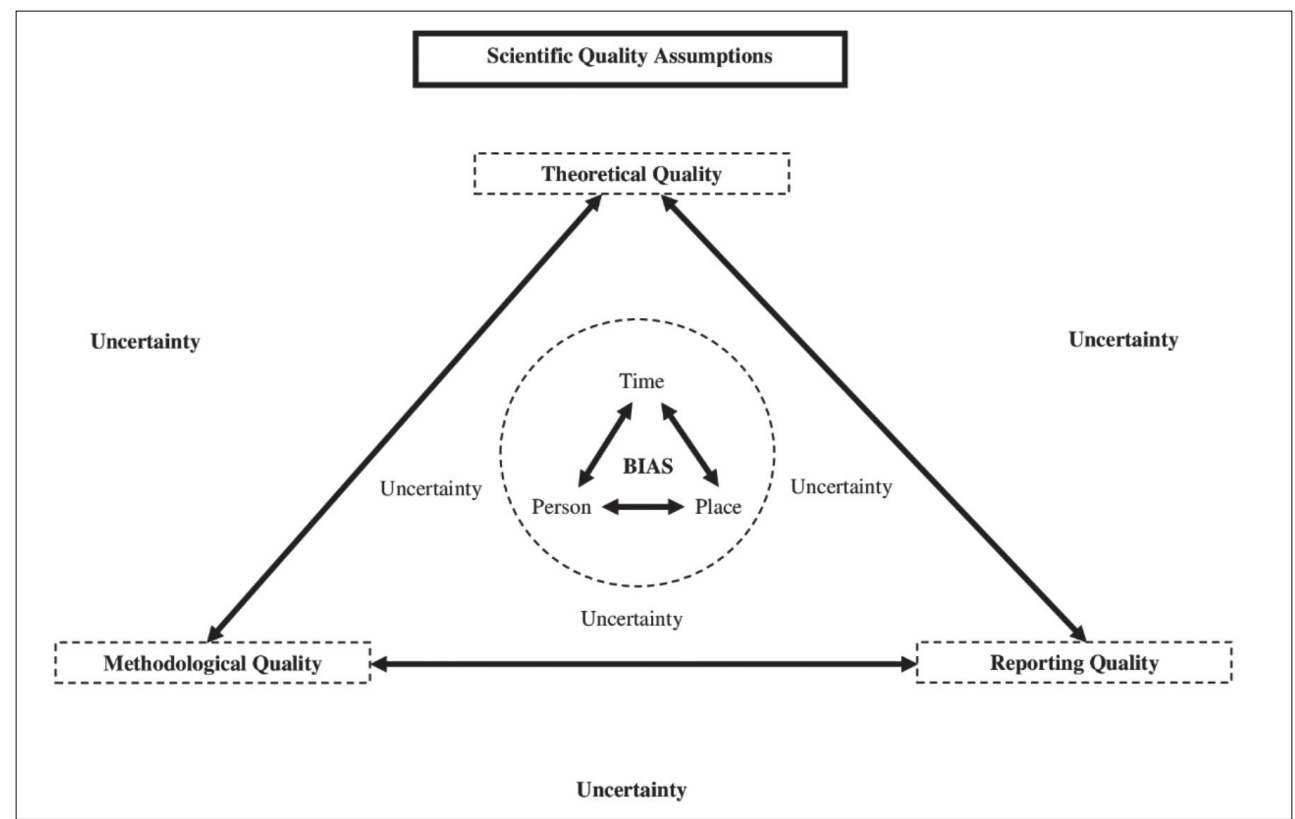

Source: the authors (2019).

Although a theoretical framework is an essential aspect of the research process (ADOM; HUSSEIN; AGYEM, 2018; CONCARI, 2001), it is often misunderstood or underestimated by researchers, with only a few in-depth reports on theory or theoretical models to support and guide scientific research (CABRERA ARANA, 2007; CABRERA ARANA; MOLINA MARÍN; RODRÍGUEZ TEJADA, 2005). 
The development of a theoretical framework is often the result of the researcher's ontological (nature of being) and epistemological (knowledge theory) perspectives (HEALE; NOBLE, 2019). Under-reporting and lack of explanation of theories or theoretical models in epidemiological studies can limit the understanding and critical assessment of readers regarding both the theoretical model used as well as the broader study. Thus, the theoretical framework must be clearly identified and made explicit in any research or scientific publication, to guide the research team as well as the reader (COUGHLAN; CRONIN; RYAN, 2007). All studies, irrespective of whether they use qualitative, quantitative, or mixed methods, must be linked to a theory and/or theoretical model and a theoretical and conceptual framework that guides all stages of the study (ROCCO; PLAKHOTNIK, 2009).

However, theory is not always valued as many authors consider it secondary to empirical results and scientific evidence (BELLER; BENDER, 2017). Social constructionists, for example, advocate against using theories a priori, preferring that theorization arise from data analysis. They claim that, given the nature of social phenomena, no previously selected theory could account for actual observations and that the adoption of a theoretical framework before the data collection phase can obscure the researcher's view. Nevertheless, they advocate the use of theory in the final project as researchers are expected to theorize based on the data (ALVES-MAZZOTTI, 2001).

Post-positivists as well as many theorists and theoretical critics recommend the use of theory in formulating hypotheses and identifying categories of analysis. They claim that it is difficult for a researcher to start collecting data without a theoretical framework, and emphasize that absence of criteria for data collection can result in loss of time, collection of excess data, and difficulty in interpretation (ALVESMAZZOTTI, 2001).

Theory-oriented thinking and action is particularly important when selecting a topic, developing research questions, conceptualizing the literature review, defining the methodological approach, and performing data analysis (DAVIES; WALKER; GRIMSHAW, 2010). Moreover, a good structure and theoretical framework facilitates result interpretation, discussion, and reflection, in addition to the identification of limitations, which contributes to cohesive and coherent conclusions (ADOM; HUSSEIN; AGYEM, 2018; GRANT; OSANLOO, 2014). 
Thus, the framework must be reported in depth at all stages of the article (HEALE; NOBLE, 2019; CABRERA ARANA, 2007).

The lack of theoretical reports in epidemiological studies may be related to the scarcity of instruments to guide researchers on how to report the theoretical bases with quality and completeness. The main instruments with reporting guidelines (MOHER et al., 2010; LIBERATI et al., 2009; VANDENBROUCKE et al., 2007) are mainly focused on methodological issues associated with specific study designs, and thus, neither deepen theoretical issues nor relate them to research.

Based on the theoretical model of assumptions for scientific quality, this study aims to present a document of the elaboration and explanation of a checklist to improve the report quality of the theory or theoretical models used in epidemiological studies. It also provides a methodological background, examples of published articles, and consistent reports for each item of the instrument. We believe that this instrument can help researchers better report the theory or theoretical model guiding their study.

\section{Developing of the Checklist for Theoretical Reporting in Epidemiological Studies (CRT-EE)}

The checklist for reporting of theory/theoretical model in epidemiological studies was developed for helping researchers better report the theory guiding their study, and for making author suggestions that can facilitate the development of more transparent and complete theoretical reports. This tool was not designed to assess the quality of the studies, nor does it refer directly, or in detail, to the methodological and practical aspects of research, for which other guides are available (STERNE et al., 2019; STERNE et al., 2016; HIGGINS; GREEN, 2011).

A theoretical model was developed before developing the checklist (figure 2), which comprises important dimensions and variables related to the quality of theoretical reporting in epidemiological studies, identified through literature reviews and previous knowledge. 
Figure 2. Theoretical model developed using the theory of meaningful learning and literature review

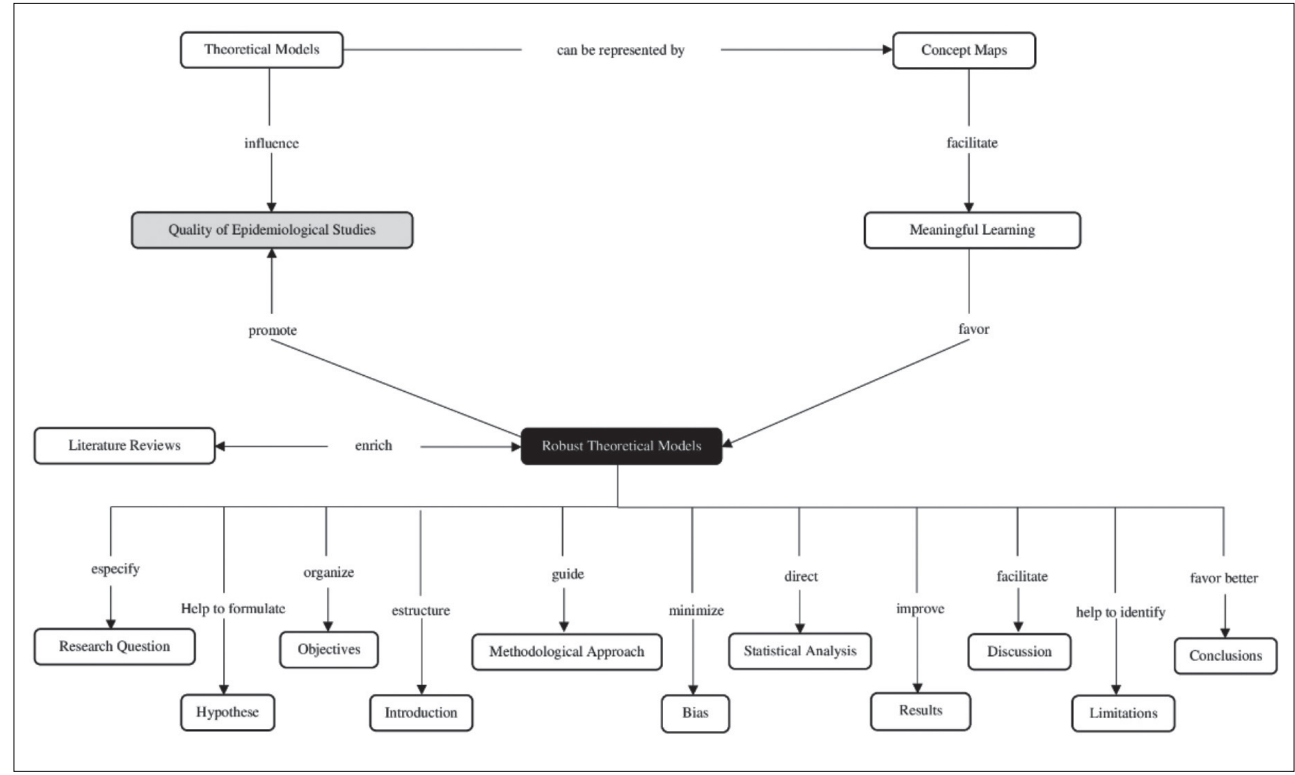

Source: the authors (2019).

A narrative literature review was conducted from July 2018 to August 2019 using the main databases: MEDLINE (Medical Literature Analysis and Retrieval System Online) at the PubMed; SciELO (Scientific Electronic Library Online) and LILACS (Literatura Latino-Americana e do Caribe de Informação em Ciências da Saúde, in Portuguese) at the BVS (Biblioteca Virtual de Saúde); SCOPUS and Web of Science via the portal of CAPES journals. There were no restrictions on the publication date. The articles were written in Portuguese, English, and Spanish. The DeCS/MeSH keywords and descriptors used in the search strategy were: Teoria/Theory; Modelos Teóricos/Models, Theoretical; Quadro Teóricol Theoretical Framework; Lista de Checagem/Checklist; Guia/Guideline; Relatório de Pesquisa/Research Report; Avaliação da Qualidade/Quality Evaluation; and Estudos Epidemiológicos/ Epidemiologic Studies. The Boolean operator AND was used to ensure greater specificity of the findings and the Boolean operator OR was used to combine the terms.

A narrative review consists of a qualitative synthesis study in which the authors are free to interpret and critically analyze literature findings (ROTHER, 2007). 
Moreover, it is an appropriate method to describe and broadly discuss the state-ofthe-art of specific subjects from a theoretical point of view. Such a review has an important role in continuing education, as it allows researchers to quickly determine the state-of-the-art for a given subject (ROTHER, 2007). However, narrative reviews may have significant limitations as they are not imperative for methodological rigor, which may make it impossible for other researchers to reproduce them (COOK, 1997; CORDEIRO et al., 2007; ROTHER, 2007). Despite these limitations, this method, which was used for developing a conceptual theoretical model that guided the development of the checklist, contributes significantly to scientific literature and researchers through debate, reflection, and promotion of this topic in the context of epidemiological research (SOUZA FILHO; STRUCHINER, 2021).

Data were selected and extracted by the first author. The articles were read in full, and then categorized and analyzed to support and strengthen the authors' line of reasoning and the scientific validity of the findings. A qualitative synthesis of the topics related to the development of theoretical models was performed. Thus, the quality of the studies included in this review was not evaluated. We prepared a table with the main studies to use as a basis for the development of the checklist (available in the supplementary file). The studies are not directly related to each other, with the relationships being identified during a critical analysis of the content. Furthermore, meetings were held so that the specialists could decide together on the items that would make up the final version of the checklist.

We do not seek to resolve the debate on the topic, but to present a line of reasoning that shows the importance of this debate for a general audience and our view on this matter.

\section{How to use the Checklist for Theoretical Reporting in Epidemiological Studies (CRT-EE)}

The Checklist for Theoretical Reporting in Epidemiological Studies (table 1), was prepared and was based on other reporting guidelines (MOHER et al., 2010; LIBERATI et al., 2009; VANDENBROUCKE et al., 2007), to standardize and make this article relatable and facilitate the involvement and understanding of readers. The purpose of this checklist is to help researchers, reviewers, and editors in the preparation of more transparent and complete theoretical reports. In this article, 
we explain each item in the checklist; the supplementary file lists exemplary articles that can be considered as good reports, corresponding to each item of the instrument.

We consider that all items on the checklist are important when reporting the theory/theoretical model in scientific studies. However, we recognize that authors may need to modify or incorporate additional items for their research. It is not our intention to make scientific practice rigid, and we emphasize that the pointers we advance are only suggestions to the authors based on the reviewed literature; this is not an instrument developed to assess the quality of studies or to present methodological guidelines.

Thus, the checklist for reporting a theory/theoretical model in epidemiological studies presents a list of 15 items to be considered when reporting theoretical frameworks in studies and indicates where additional information can improve the transparency of this process. We present the items numerically according to the sections: title, abstract, introduction, methodology, results, discussion, and conclusion. Moreover, we have included a column for indicating, in a dichotomous manner (yes or no), whether the requested information for each item was included.

Unlike other reporting guidelines (MOHER et al., 2010; LIBERATI et al., 2009; VANDENBROUCKE et al., 2007), which suggest that authors do not need to address the items in a specific order, we emphasize that information for each item of our instrument should be included in the indicated sections, as these are the most suitable places for theoretical reporting according to the reviewed literature (ADOM; HUSSEIN; AGYEM, 2018; GRANT; OSANLOO, 2014; KITCHEL; BALL, 2014; IMENDA, 2014).

To emphasize to authors, and others, the importance of transparent and in-depth theoretical reporting, we encourage journals that support our Checklist to endorse it and include their email address (www.crt-statement.org) in their instructions to authors and thus encourage authors to adhere to its principles. In addition, this Checklist is registered with the EQUATOR Network, the main international initiative for the dissemination and recommendation of reporting guidelines. 
Table 1. Checklist items to be included in the theoretical report in epidemiological studies

\begin{tabular}{|c|c|c|c|}
\hline Session/topic & Item & $\begin{array}{l}\text { Checklist for Theoretical Reporting in Epidemiological Studies } \\
\text { (CRT-EE) }\end{array}$ & Answer \\
\hline \multicolumn{4}{|l|}{ TITLE } \\
\hline Title & 1 & $\begin{array}{l}\text { Did the article title mention the theory/theoretical model and the } \\
\text { related main variables that underlie the research? }\end{array}$ & $\begin{array}{l}\square \mathrm{YES} \\
\square \mathrm{NO}\end{array}$ \\
\hline \multicolumn{4}{|l|}{ ABSTRACT } \\
\hline $\begin{array}{l}\text { Reasoned } \\
\text { Abstract }\end{array}$ & 2 & $\begin{array}{l}\text { Did the article present, in the abstract, the theory/theoretical } \\
\text { model and its main related variables that underlie the research } \\
\text { and explain how they were evaluated and what the main findings, } \\
\text { potential limitations, and conclusions are, in relation to the } \\
\text { theory/theoretical model used? }\end{array}$ & $\begin{array}{l}\square \mathrm{YES} \\
\square \mathrm{NO}\end{array}$ \\
\hline \multicolumn{4}{|c|}{ INTRODUCTION } \\
\hline $\begin{array}{l}\text { Mention and } \\
\text { Refer }\end{array}$ & 3 & $\begin{array}{l}\text { Did the article explicitly mention and referenced to one or more } \\
\text { theories/theoretical models on which the study is based? (In } \\
\text { cases where the study is based on a theoretical model specifically } \\
\text { developed for the research, the authors must explicitly mention it } \\
\text { and, whenever possible, provide a reference.) }\end{array}$ & $\begin{array}{l}\square \mathrm{YES} \\
\square \mathrm{NO}\end{array}$ \\
\hline $\begin{array}{l}\text { Describe the } \\
\text { Variables }\end{array}$ & 4 & $\begin{array}{l}\text { Did the article describe the variables of the theory/theoretical } \\
\text { model and their interrelations with the research cohesively and } \\
\text { coherently? }\end{array}$ & $\begin{array}{l}\square \mathrm{YES} \\
\square \mathrm{NO}\end{array}$ \\
\hline $\begin{array}{l}\text { Review } \\
\text { Literature }\end{array}$ & 5 & $\begin{array}{l}\text { Did the article report the existence/absence of other theories/ } \\
\text { theoretical models related to the analyzed phenomenon and } \\
\text { explain the choice with scientific coherence? }\end{array}$ & $\begin{array}{l}\square \mathrm{YES} \\
\square \mathrm{NO}\end{array}$ \\
\hline $\begin{array}{l}\text { Innovation/ } \\
\text { Theoretical Gap }\end{array}$ & 6 & $\begin{array}{l}\text { Did the article report the contribution of the chosen theory/ } \\
\text { theoretical model to the phenomenon studied? }\end{array}$ & $\begin{array}{l}\square \mathrm{YES} \\
\square \mathrm{NO}\end{array}$ \\
\hline \multicolumn{4}{|c|}{ METHODOLOGY } \\
\hline $\begin{array}{l}\text { Explanatory } \\
\text { Topic }\end{array}$ & 7 & $\begin{array}{l}\text { Did the article dedicate a topic (preferably at the beginning } \\
\text { of the Methods session) to describe in depth how the theory/ } \\
\text { theoretical model guided the methodological paths developed in } \\
\text { the research? }\end{array}$ & $\begin{array}{l}\square \mathrm{YES} \\
\square \mathrm{NO}\end{array}$ \\
\hline $\begin{array}{l}\text { Graphic } \\
\text { Representation }\end{array}$ & 8 & $\begin{array}{l}\text { Did the article represented the theory/theoretical model using a } \\
\text { graph? (e.g., figure in the form of a concept map, causal diagram, } \\
\text { among other forms). When it is not available in the article, did } \\
\text { the article inform where and how it can be accessed (e.g., email } \\
\text { address, appendix, supplementary file)? }\end{array}$ & $\begin{array}{l}\square \mathrm{YES} \\
\square \mathrm{NO}\end{array}$ \\
\hline
\end{tabular}

to be continued... 


\begin{tabular}{|c|c|c|c|}
\hline Session/topic & Item & $\begin{array}{l}\text { Checklist for Theoretical Reporting in Epidemiological Studies } \\
\text { (CRT-EE) }\end{array}$ & Answer \\
\hline $\begin{array}{l}\text { Conceptualize } \\
\text { and Categorize }\end{array}$ & 9 & $\begin{array}{l}\text { Did the article conceptualize, categorize, and inform how } \\
\text { interrelated research variables in the theory/theoretical model will } \\
\text { be recorded and/or classified? }\end{array}$ & $\begin{array}{l}\square \mathrm{YES} \\
\square \mathrm{NO}\end{array}$ \\
\hline $\begin{array}{l}\text { Theoretical } \\
\text { Analysis }\end{array}$ & 10 & $\begin{array}{l}\text { Does the data analysis plan include all the variables of the theory/ } \\
\text { theoretical model related to research? If any variables have been } \\
\text { excluded or included in the analysis, please justify. }\end{array}$ & $\begin{array}{l}\square \mathrm{YES} \\
\square \mathrm{NO}\end{array}$ \\
\hline \multicolumn{4}{|l|}{ RESULTS } \\
\hline $\begin{array}{l}\text { Results of the } \\
\text { Variables }\end{array}$ & 11 & $\begin{array}{l}\text { Did the article present the results of all the variables of the } \\
\text { analyzed theory/theoretical model? If any variable has been } \\
\text { occulted, please justify. }\end{array}$ & $\begin{array}{l}\square \mathrm{YES} \\
\square \mathrm{NO}\end{array}$ \\
\hline $\begin{array}{l}\text { Theoretical } \\
\text { Impact }\end{array}$ & 12 & $\begin{array}{l}\text { Did the article report how the study's findings impact the theory/ } \\
\text { theoretical model and explanation the final Theory/Theoretical } \\
\text { Model? In the same way as in item 8: (for instance, figure in the } \\
\text { form of concept map, causal diagram, among other forms) and } \\
\text { when necessary (e.g., email address, appendix, supplement file). }\end{array}$ & $\begin{array}{l}\square \mathrm{YES} \\
\square \mathrm{NO}\end{array}$ \\
\hline \multicolumn{4}{|l|}{ DISCUSSION } \\
\hline $\begin{array}{l}\text { Discussion and } \\
\text { Reflection }\end{array}$ & 13 & $\begin{array}{l}\text { Did the article discuss the study's findings cohesively and } \\
\text { coherently based on the interrelations expected and those } \\
\text { found using the theory/theoretical model adopted and other } \\
\text { existing ones? }\end{array}$ & $\begin{array}{l}\square \mathrm{YES} \\
\square \mathrm{NO}\end{array}$ \\
\hline Limitations & 14 & $\begin{array}{l}\text { Did the article describe the limitations of the theory/theoretical } \\
\text { model (e.g., theory/theoretical model simplified or incomplete } \\
\text { and possible exclusions of variables in the analysis)? }\end{array}$ & $\begin{array}{l}\square \mathrm{YES} \\
\square \mathrm{NO}\end{array}$ \\
\hline \multicolumn{4}{|l|}{ CONCLUSION } \\
\hline Conclusions & 15 & $\begin{array}{l}\text { Did the article present a general interpretation of the theory/ } \\
\text { theoretical model used in the study considering other theories/ } \\
\text { theoretical models regarding potentialities, gaps, and implications } \\
\text { for future studies on this theory/theoretical model? }\end{array}$ & $\begin{array}{l}\square \mathrm{YES} \\
\square \mathrm{NO}\end{array}$ \\
\hline
\end{tabular}

Source: the authors (2019). 


\section{Explanation of the items of the Checklist for Theoretical Reporting in Epidemiological Studies (CRT-EE)}

\section{TITLE}

\section{Item 1: Title}

Did the article title mention the theory/theoretical model and the related main variables that underlie the research?

\section{Explanation}

Authors should objectively identify the theory/theoretical model and the main variables related to the study in the title. A title containing this information can increase the interest of readers; facilitate their understanding; and stimulate new studies, reviews, and systematic reviews on the theoretical perspective, as the first stage of the search and selection of documents commonly involves reading the titles of works (BOOTH; CARROLL, 2015).

Authors often choose titles for their articles that incorporate the main exposure and outcome variables used in the study, which can make it difficult to identify and understand the variables related to the Theory/Theoretical Model. The variables related to the objective of the study are encompassed within the theoretical body, which can contain different constructs for the same relationship. Thus, readers need to read other sections of the article to find theoretical information, and thus, judge the relevance of the article to their work, as shown in the example: "Fear of falling and risk of falling: A systematic review and meta-analysis" (PENA et al., 2019).

This title does not mention the theory/theoretical model used in the article. The main variables (exposure and outcome) of the study ("fear of falling" and "risk of falling") and the study design are described. Thus, it is necessary to read other sections to understand the theoretical basis of the study. In the Introduction section, this article presents several theoretical models for the "fear of falling" concept and its interrelation with the "risk of falling" and states that the variations are due to multifactorial phenomena and cognitive, physiological, and behavioral elements (PENA et al., 2019).

These theoretical differences may impact the choice of variables in the theoretical model and, consequently, modify the interpretation of the findings and its replicability 
and reproducibility. A reader interested in a particular theoretical approach would have to read the entire article to obtain this fundamental information.

Thus, identifying and mentioning the theory/theoretical model and its main related variables could facilitate the acquisition of information about the article, increasing the interest of readers and the likelihood of reading.

\section{ABSTRACT}

\section{Item 2: Reasoned Abstract}

Did the article present, in the abstract, the theory/theoretical model and its main related variables that underlie the research and explain how they were evaluated and what the main findings, potential limitations, and conclusions are, in relation to the theory/theoretical model used?

\section{Explanation:}

The Abstract section provides important information that allows readers to quickly understand how the research was developed from conception to completion, presenting the objectives, methodological procedures, expected and obtained results, potential limitations, and related conclusions. Complete descriptions can increase the reader's interest and the likelihood of reading the entire article. We suggest the inclusion of the theoretical report in the Abstract section as it could facilitate readers' understanding and critical analysis. The preparation of structured abstracts is desirable as they provide readers with more complete and easily located information.

The scientific literature shows that a structured abstract can include: Introduction (or Context), Objective (or Purpose), Methods (or Methodological Procedures), Results, Limitations (when applicable), and Conclusions (or implications) (LIBERATI et al., 2009). Thus, we suggest the inclusion of a synthetic reporting of the theoretical and conceptual framework, how it guided the study, and how the research results may impact the theoretical framework, as reported in the body of the article.

We suggest that authors mention not only the main exposure and outcome variables in the Objective, but also the theory/theoretical model used in the study. In the Methods section, we suggest describing the main variables directly or indirectly related to the theoretical basis and providing a brief explanation of the method used for collecting the variables and their inclusion in the analysis, justifying, when necessary, the exclusion or inclusion of variables related to the theoretical model 
used in the study. In the Results section, we suggest reporting the main findings obtained from the included and excluded variables (if applicable) of the Theory/ Theoretical Model. Finally, in the Limitations and Conclusion sections, we suggest reporting the main limitations and conclusions of the Theory/Theoretical Model, positive and negative aspects compared to other theories, gaps, and implications for future research related to the theory/theoretical model chosen.

We understand that many journals impose stringent limits on the number of characters and/or words for the Abstract section, which can make it difficult to present an in-depth theoretical framework. However, the synthetic description of the article in the Abstract section will be the result of an understanding of the relationship between the theoretical and conceptual framework of the research and its methods of preparation, results, and developments, which can be a challenging but instinctive task for researchers. Journals' editors should consider making more space available for allowing a complete and robust presentation of pertinent information in scientific articles.

\section{INTRODUCTION}

The introduction, a section in which authors commonly find more freedom to contextualize the study, provides a better understanding of the theoretical bases that guide the research. The theory or model can be presented more broadly and descriptively, sharing information on the references, its scientific validity, the existence of other similar theories or gaps in the literature, and the reasons that guided the choice of the theory/theoretical model based on hypotheses on how it could contribute to the phenomenon in the article.

Thus, we suggest reporting the theoretical and conceptual framework transparently and completely in the Introduction section, describing the related variables and presenting other Theories/Theoretical Models, and justifying the choice and presenting its limitations and potentialities.

Thus, we developed the following items:

\section{Item 3: Mention and Refer}

Did the article explicitly mention and referenced to one or more Theories/ Theoretical Models on which the study is based? (In cases the study is based on a 
theoretical model specifically developed for the research, the authors must explicitly mention it and, whenever possible, provide a reference.)

\section{Explanation:}

Authors should mention and referenced the theory/theoretical model that guided the research, as there may be theories or models with the same name, but with different conceptual and structural aspects for the same research relationship. Thus, the accurate reporting of this information facilitates the reader's identification of the study's theoretical orientation and an analysis of the potentialities and limitations arising from the researcher's theoretical choice.

Moreover, in this case, as the study is based on an original theoretical model that was specifically developed for the study, it is important to explicitly mention it and provide a reference, allowing readers to access the model and analyze the validity of the theoretical and conceptual framework developed and presented by the authors.

Thus, we suggest that these explanations should be included in the opening paragraphs (example 1 in the supplementary file) and reinforced in the last paragraph of the Introduction section, which is commonly used to describe the objective of the study (example 2 in the supplement).

\section{Item 4: Describe the Variables}

Did the article describe the variables of the theory/theoretical model and their interrelations with the research cohesively and coherently?

\section{Explanation:}

Once the theory or theoretical model that guides the study is mentioned, we suggest including the description of the variables related to the study and those corresponding to the possible dimensions included in the theoretical and conceptual structure of the research. The objective of a robust presentation of the conceptual framework is to categorize and describe concepts relevant to the study and map the relationships between them (HEALE; NOBLE, 2019; IMENDA, 2014).

Thus, we suggest that the authors provide detailed information about the variables and their interrelationships according to the theoretical and conceptual frameworks presented in the study. Omitting or not justifying the inclusion or exclusion of variables related to the theory or model can make it difficult for 
readers to understand, generate doubts regarding the potential of the theoretical choice for the study, impact the analysis plan and statistical findings and their interpretation (GRANT; OSANLOO, 2014).

\section{Item 5: Review Literature}

Did the article report the existence/absence of other Theories/Theoretical Models related to the analyzed phenomenon and explain the choice with scientific coherence?

\section{Explanation:}

This item suggests the integrated review, criticism, and synthesis of the representative literature on the topic with the theory or theoretical model that guides the research so that new frameworks, insights, and perspectives are generated. Thus, we suggest that the authors present initial holistic conceptualizations about the phenomenon and theory and information about other theories or models related to the studied phenomenon that can provide a new understanding and theoretical concepts.

Moreover, reporting this information facilitates the reader's reflection on the authors' justification of the theoretical choice to support and guide their research. Moreover, a good structure and theoretical framework favor the interpretation of results, discussions, and critical reflections, and the identification of limitations, which contributes to reaching cohesive and coherent conclusions based on the theory or theoretical model used in the research (ADOM; HUSSEIN; AGYEM, 2018; GRANT; OSANLOO, 2014).

\section{Item 6: Innovation/Theoretical Gap}

Did the article report the contribution of the chosen theory/theoretical model to the phenomenon studied?

\section{Explanation:}

It is desirable to present possible gaps or innovations in the developed, adapted, or chosen theory and their relationship with identifying possible research hypotheses, the potentialities of the theory/theoretical model used to answer these hypotheses, and the possible implications of the research results for the theoretical framework. 
It is important that the author not only describes and presents the theory based on its relevance but also recognizes the possible gaps and insights that were not foreseen by the theory and expands the knowledge on the topic. This practice can improve the readers' understanding of the author's hypotheses and intentions regarding the study object.

Thus, we suggest that such information should be described in the last paragraphs of the Introduction section being reinforced in the paragraph that contains the objectives of the study in the same section of the article.

\section{METHODOLOGY}

This session presents to the reader the detailed theoretical basis used in the research and the Theory and/or Theoretical Model that guided the methodological path used for searching, analyzing, and interpreting the findings.

Thus, we suggest the inclusion of a detailed topic on how the theory or theoretical model was used and operationalized for choosing the methodology; the included and excluded variables with their respective justification and how the conceptual theoretical framework conducted the analysis. The graphical presentation of the theoretical model is an attempt to provide greater clarity about the variables involved and their relationships to the reader and the researchers involved in the research to: facilitate the identification of the variables of interest and their interrelationships; promote greater meaningful learning of the phenomenon studied; enable the continuous improvement of the model by including or excluding variables and identifying new relationships not initially considered; minimize bias and improve the methodology; among other aspects.

\section{Item 7: Explanatory Topic}

Did the article dedicate a topic (preferably at the beginning of the Methods session) to describe in depth how the theory/theoretical model guided the methodological paths developed in the research?

\section{Explanation:}

The literature highlights the important role of mechanisms, which are essential in the evaluation of the methodological process (MOORE et al., 2019). Describing 
the theory model transparently provides greater clarity and consistency in choosing the methodological path.

For example, the descriptions of complex interventions often lack details necessary to facilitate their replication and reproducibility by other researchers. Hence, we emphasize the importance of implementing reporting guidelines for transparent articles, which also includes the theoretical aspects that underlie the studies, given their importance in the study design, discussion, and comparison of the results and their potential to aggregate innovations or modify established scientific knowledge.

Thus, we suggest that journals recommend authors to include a topic that addresses the contextual and structural aspects related to the theories and/or theoretical models used in their studies. It is important to include detailed descriptions of the main aspects of the model, including the hypotheses about the relationships, the role of the variables, and the meaning of the symbols in the graphic model and/or unconventional terms used by the authors, facilitating the readers' understanding.

Nonetheless, it may not be possible to present the complete information due to the restricted space commonly imposed by journals. We suggest that, along with the topic summarized in the body of the article, authors can present detailed information on other platforms such as other published articles, appendices, supplement files, web pages, among others.

\section{Item 8: Graphic Representation}

Did the article represented the theory/theoretical model using a graph? (e.g.,. figure in the form of a concept map, causal diagram, among other forms). When it is not available in the article, did the article inform where and how it can be accessed (e.g., email address, appendix, supplementary file)?

\section{Explanation:}

A graphical representation can be more effective than a text for the communication of complex contents (VEKIRI, 2002). This is because the mental processing of images causes less cognitive overload than the verbal processing of a text.

Allan Paivio (1991) presents the Dual Coding Theory, which indicates the existence of two interrelated cognitive subsystems: the imagetic, concerning non-verbal objects and elements; and the verbal, combined with language. The relationship between the two cognitive systems causes information to be coded in a 
dual way, which facilitates the understanding of the relationships and connections established in the cognitive structure.

Thus, we consider graphic representation to be a component that can improve and facilitate the mechanisms of decoding and recoding of language by readers and researchers. Thus, we consider the graphic explanation, by the authors, of the Theory and/or Theoretical Model on which the study is based to be important, whether through conceptual maps, causal diagrams, or others.

This practice can facilitate readers' understanding and interpretation of the research and, consequently, its replicability and scientific reproducibility. It could also help identify possible mistakes or the need to improve the theoretical model used or to include or exclude variables (PEARL; MACKENZIE, 2018).

Thus, we suggest graphical representation should be included in the Methodology section, and whenever possible, accompanied by a brief text that addresses the pertinent relationships in the figure, which may appear together with the explanatory topic described in the previous item. If necessary, the authors can, in addition to explaining the illustration in the body of the article, provide supplement files that explain the graphic or other illustrations that are necessary in greater depth.

\section{Item 9: Conceptualize and Categorize}

Did the article conceptualize, categorize, and inform how interrelated research variables in the theory/theoretical model will be recorded and/or classified?

\section{Explanation:}

There may be different ways conceptualize, categorize, and record the same variable within the same theoretical framework or model (HEALE; NOBLE, 2019; ADOM; HUSSEIN; AGYEM, 2018). Thus, we suggest that the authors describe these in detail in the study according to the theoretical framework to allow the reader to understand how the variables of the theoretical model were operationalized.

Such information about the operationalization process of the variables allows readers to make reflective criticisms about the theoretical conceptual structure and methods of collecting and recording the data used in the research. It also facilitates the repeatability and reproducibility of the studies as it favors understanding the rationale used by the author in the interaction and transposition of concepts/ constructs and variables between the theoretical and empirical levels. 
For cases in which the theory or theoretical model of the study has a high number of variables that require many words for their detailed description in the article, the authors may make this information available as a supplement file or link to provide access to the readers as shown in the follwing example: "A questionnaire was developed according to the guidelines for Theory of Planned Behavior surveys. It contained 23 question items (Additional file 1: Table S1), measuring attitudes, subjective norms, perceived behavioral control and behavioral intentions of the prescribers" (LIU et al., 2019).

\section{Item 10: Theoretical Analysis}

Does the data analysis plan include all the variables of the theory/theoretical model related to research? If any variables have been excluded or included in the analysis, please justify.

\section{Explanation:}

The detailed explanation of the analysis method used for the variables related to the theory and/or model and the explanation and justification of the variables included and excluded for analysis is part of the transparency of the scientific report, indicating that the authors are coherent with the conceptual theoretical framework and consider the most recent scientific evidence on the subject.

Thus, it is desirable that the authors, along with explaining all the variables related to the theoretical and conceptual structure of the research in the previous items, describe how the theoretical model influenced the choice of methods for analyzing the variables, thus, presenting explaining their inclusion and exclusion according to the hypotheses and the role of the variables in the theoretical model. We suggest that the authors should identify and classify the variables (as confounding or mediating, for example) and justify when necessary. If the theoretical model used for the analysis is different from the initially developed conceptual theoretical model, a new graphical representation of the theoretical model of analysis can be presented by the authors along with the textual explanation.

Many studies briefly report the methods of analysis and the criteria used to include or exclude variables for analysis. Simplifying variables in the theoretical framework for analysis can lead to simplified research results subject to bias and different from analyses based on more robust and complete theoretical models (JAHN-EIMERMACHER et al., 2017). 


\section{RESULTS}

\section{Item 11: Result of the Variables}

Did the article present the results of all the variables of the analyzed Theory/ Theoretical Model? If any variable has been occulted, please justify.

\section{Explanation:}

In the Results section, the authors should report the findings referring to all analyzed variables, which were chosen based on the theory and/or theoretical model, and present justifications related to possible exclusions or inclusions of variables from the initial theoretical model.

Changes in the initial conceptual variables can generate changes in the results of the study, over-or under-estimating values and relationships according to the theoretical structure (JAHN-EIMERMACHER et al., 2017). Moreover, it may be difficult to determine causal mechanisms, rely on generalization to other populations, or establish the clinical significance of the effects of the intervention in a study that does not define a theoretical framework in the context of mixed methods to capture the complexity of the examined relationships (EVANS; COON; UME, 2011). Hence, it is important to present the results for each variable related to the theoretical structure, including those in which had no relation or statistical significance and may have been excluded from the initial theoretical model.

In all causal modeling, the interpretations should raise questions about the ethics and feasibility of the interventions implicit in the effect definitions (WESTREICH; GREENLAND, 2013). Thus, the presentation of estimates for all variables included in the model can generate misinterpretations related to possible direct or indirect effects which will require attention in the reporting and interpretation of the results. Thus, we recommend presenting the effect estimates, when necessary, according to the type of estimated effect related to the theoretical model.

\section{Item 12: Theoretical Impact}

Did the article report how the study's findings impact the theory/theoretical model and show it in the final theory/theoretical model (in the same way as in item 8; for instance, figure in the form of concept map, causal diagram, among other forms)? 


\section{Explanation:}

We suggest the description and explanation, in the Results section, of the possible impacts of the findings on the theory and/or model used in the research. Moreover, it would be interesting to present the graphical representation of the new theoretical model, which was adjusted based on the possible impacts of the results, when applicable, to allow comparison with the initial theoretical model.

The results of theories or models in epidemiological studies can vary for several reasons, whether they are related to time, person, and/or place. Such changes need to be reported in the article so that readers identify the scope of the theoretical model and its impacts on the theory under analysis. In this way, readers will be able to determine how the theoretical and conceptual framework used in the research varies according to a certain temporality, individuality, and/or environment, improving scientific reproducibility, bringing greater reliability to the findings, and showing its potential limitations.

\section{DISCUSSION}

\section{Item 13: Discussion and Reflection}

Did the article discuss the study's findings cohesively and coherently based on the interrelations expected and those found using the Theory/Theoretical Model?

\section{Explanation:}

We emphasize the importance of describing and discussing the study's findings with the theoretical basis for the research, considering the expected results, the inclusion and exclusion criteria of variables in the analysis model and the limitations related to the theoretical model. Moreover, we suggest the incorporation of other theories or theoretical models in the discussion, contrasting the results of the study with other theoretical references.

Different contexts can influence the results and their interpretations, requiring that the authors not be guided only by the empirical findings but also consider the theoretical and conceptual framework used for the research (JAHN-EIMERMACHER et al., 2017; ADOM; HUSSEIN; AGYEM, 2018; GRANT; OSANLOO, 2014). Thus, it is important to consider that findings with statistical significance do not always suggest clinical, political, or other relevance. Similarly, a non-significant result does not necessarily determine the permanence or exclusion of a particular variable in the 
theoretical model. For this, it is necessary to analyze a complex causal chain and the results of several studies on the topic, considering uncertainty.

Hence, we believe that along with comparisons and discussions about empirical data (often presented as the main factor in a study), the theoretical report should be discussed, compared, criticized, and a matter of reflection for the researchers. Moreover, a discussion section should be well guided by the theoretical framework to enable richer discussions and allow critical reading by readers (GRANT; OSANLOO, 2014).

\section{Item 14: Limitations}

Did the article describe the limitations of the theory/theoretical model (e.g., theory/theoretical model simplified or incomplete and possible exclusions of variables in the analysis)?

\section{Explanation:}

We suggest reporting, in a transparent manner, the possible limitations of the theory or model and its possible impacts on the results. These limitations should be completely described so that readers will be able to analyze in detail the potentialities and weaknesses of the theory and reflect on the quality of research, allowing the development of improved studies in the future.

\section{CONCLUSION}

\section{Item 15: Conclusions}

Did the article present a general interpretation of the theory/theoretical model used in the study considering other Theories/Theoretical Models regarding potentialities, gaps, and implications for future studies on this Theory/Theoretical Model?

\section{Explanation:}

We suggest that the authors present, in their final considerations, a general interpretation of the theory/theoretical model used in the study and its relationship with other Theories/Theoretical Models, as reported in the other sections of the article. The objective is to briefly defend their positions and points of view regarding the findings, potentialities, gaps, and implications of their article for future studies. 


\section{Final considerations}

We wrote this explanatory article to discuss the importance of reports transparent and complete regarding the theoretical aspects that fundamentals and guide research. Throughout the text, we explain why the items were included in the checklist, with examples of published articles that we consider to be good reports (in the supplementary file). We hope that the presented material helps authors and editors use the checklist.

The Checklist for Theoretical Reporting in Epidemiological Studies provides recommendations for researchers to report, in a transparent way, aspects related to the theory/theoretical model they used in their epidemiological studies. A proper report reveals the strengths and weaknesses of a study and facilitates the interpretation and application of the research results (ADOM; HUSSEIN; AGYEM, 2018; VANDENBROUCKE et al., 2007).

Moreover, this Checklist can help in the planning of epidemiological studies associated with other methodological and reporting guidelines specifically developed for study design and methodological issues (STERNE, J. A. C. et al., 2019; SHEA et al., 2017; STERNE, J. A. et al., 2016; HIGGINS; GREEN, 2011; MOHER et al., 2010; LIBERATI et al., 2009; VANDENBROUCKE et al., 2007), which can positively impact the quality of the research. Furthermore, our instrument can guide editors and peer reviewers in evaluating and identifying the use and depth of the theories and theoretical models in manuscripts.

We emphasize that, similar to other recommendations and reporting guidelines (LIBERATI et al., 2009; MOHER et al., 2010; SHEA et al., 2017; STERNE, J. A. C. et al., 2019), the Checklist for Theoretical Reporting in Epidemiological Studies and the Theory of Scientific Quality Assumptions that underlies it, are under development, which can be considered a limitation of this study. We emphasize the importance of continuous evaluation, refinement, and, if necessary, alteration. Thus, the principles and items presented in this article and the checklist are open to change based on new evidence and critical comments.

Therefore, we invite all readers and future supporters of our instrument to share critiques and suggestions relating to our checklist, so that we can improve the theoretical report in epidemiological studies. ${ }^{1}$ 


\section{Acknowledgements}

We thank the Coordination for the Improvement of Higher Education Personnel - Brazil (Coordenação de Aperfeiçoamento de Pessoal de Nivel Superior - CAPES) for funding the research - Financing Code 001.

\section{References}

ADOM, D.; HUSSEIN, E. K.; AGYEM, J. A. Theoretical and Conceptual Framework: Mandatory Ingredients of a Quality Research. International Journal of Scientific Research, [s. 1.], v. 7, n. 1, p. 438-441, 2018.

ALVES-MAZZOTTI, A. J. Relevância e Aplicabilidade da Pesquisa em Educação. Cadernos de Pesquisa, [s. 1.], v. 12, n. 113, p. 39-50, 2001.

BELLER, S.; BENDER, A. Theory, the Final Frontier? A Corpus-Based Analysis of the Role of Theory in Psychological Articles. Frontiers in Psychology, [s. 1.], v. 8, p. 951, 2017. Disponível em: <https://doi.org/10.3389/fpsyg.2017.00951>

BOOTH, A.; CARROLL, C. Systematic Searching for Theory to Inform Systematic Reviews: Is it Feasible? Is it Desirable? Health Information \& Libraries Journal, [s. 1.], v. 32, n. 3, p. 220235, 2015. Disponível em: <https://doi.org/10.1111/hir.12108>

CABrera ARANA, G. A. Uso de Teorías y Modelos en Artículos de una Revista Latinoamericana de Salud Pública, 2000-2004. Revista de Saúde Pública, [s. 1.], v. 41, n. 6, p. 963-969, 2007. Disponível em: <https://doi.org/10.1590/S0034-89102007000600011>

CABRERA ARANA, G.; MOLINA MARÍN, G.; RODRÍGUEZ TEJADA, C. Base Teórica en una Muestra de Investigaciones de la Facultad Nacional de Salud Pública-Universidad de Antioquia, Colombia 1965-2004. Revista de Salud Pública, [s. 1.], v. 7, n. 1, p. 99-111, 2005. Disponível em: <https://doi.org/10.1590/S0124-00642005000100008>

CONCARI, S. B. Las Teorías y Modelos en la Explicación Científica: Implicancias para la Enseñanza de las Ciencias. Ciência \& Educação (Bauru), [s. 1.], v. 7, n. 1, p. 85-94, 2001. Disponível em: <https://doi.org/10.1590/S1516-73132001000100006>

COOK, D. J. Systematic Reviews: Synthesis of Best Evidence for Clinical Decisions. Annals of Internal Medicine, [s. 1.], v. 126, p. 376, 1997. Disponível em: <https://doi.org/10.7326/00034819-126-5-199703010-00006>

CORDEIRO, A. M. et al. Revisão Sistemática: Uma Revisão Narrativa. Revista do Colégio Brasileiro de Cirurgiöes, [s. 1.], v. 34, p. 428-431, 2007. Disponível em: <https://doi.org/10.1590/ S0100-69912007000600012> 
COUGHLAN, M.; CRONIN, P.; RYAN, F. Step-by-step Guide to Critiquing Research. Part 1: Quantitative Research. British Journal of Nursing, [s. 1.], v. 16, n. 11, p. 658-663, 2007. Disponível em: <https://doi.org/10.12968/bjon.2007.16.11.23681>

DAVIES, P.; WALKER, A. E.; GRIMSHAW, J. M. A Systematic Review of the Use of Theory in the Design of Guideline Dissemination and Implementation Strategies and Interpretation of the Results of Rigorous Evaluations. Implementation Science, [s. 1.], v. 5, n. 14, p. 1-6, 2010. Disponível em: <https://doi.org/10.1186/1748-5908-5-14>

EVANS, B. C.; COON, D. W.; UME, E. Use of Theoretical Frameworks as a Pragmatic Guide for Mixed Methods Studies: A Methodological Necessity? Journal of Mixed Methods Research, [s. 1.], v. 5, n. 4, p. 276-292, 2011. Disponível em: <https://doi. org/10.1177/1558689811412972>

GRANT, C.; OSANLOO, A. Understanding, Selecting, and Integrating a Theoretical Framework in Dissertation Research: Creating the Blueprint for Your "House". Administrative Issues Journal Education Practice and Research, [s. 1.], v. 4, n. 2, p. 12-26, 2014. Disponível em: <https://doi.org/10.5929/2014.4.2.9>

HEALE, R.; NOBLE, H. Integration of a Theoretical Framework into your Research Study. Evidence Based Nursing, [s. 1.], v. 22, n. 2, p. 36-37, 2019. Disponível em: <https://doi. org/10.1136/ebnurs-2019-103077>

HIGGINS, J. P. T.; GREEN, S. Cochrane Handbook for Systematic Reviews of Interventions. [S. 1.], 2011. <Disponível em: https://handbook-5-1.cochrane.org/>. Acesso em: 11 set. 2019.

IMENDA, S. Is There a Conceptual Difference between Theoretical and Conceptual Frameworks? Journal of Social Sciences, [s. 1.], v. 38, n. 2, p. 185-195, 2014. Disponível em: <https://doi.org/10.1080/09718923.2014.11893249>

JAHN-EIMERMACHER, A. et al. A DAG-based Comparison of Interventional Effect Underestimation Between Composite Endpoint and Multi-state Analysis in Cardiovascular Trials. BMC Medical Research Methodology, [s. 1.], v. 17, n. 1, p. 92, 2017. Disponível em: <https://doi.org/10.1186/s12874-017-0366-9>

KITCHEL, T.; BALL, A. L. Quantitative Theoretical and Conceptual Framework Use in Agricultural Education Research. Journal of Agricultural Education, [s. 1.], v. 55, n. 1, p. 14, 2014. Disponível em: <https://doi.org/10.5032/jae.2014.01186>

LIBERATI, A. et al. The PRISMA Statement for Reporting Systematic Reviews and MetaAnalyses of Studies That Evaluate Health Care Interventions: Explanation and Elaboration. Annals of Internal Medicine, [s. 1.], v. 151, n. 4, p. W65-W94, 2009. Disponível em: <https://doi. org/10.7326/0003-4819-151-4-200908180-00136> 
LIU, C. et al. Determinants of Antibiotic Prescribing Behaviors of Primary Care Physicians in Hubei of China: A Structural Equation Model Based on the Theory of Planned Behavior. Antimicrobial Resistance \& Infection Control, [s. 1.], v. 8, n. 23, p. 8, 2019. Disponível em: <https://doi.org/10.1186/s13756-019-0478-6>

MOHER, D. et al. CONSORT 2010 Explanation and Elaboration: Updated Guidelines for Reporting Parallel Group Randomised Trials. BMJ, [s. 1.], v. 340, n. 1, p. c869-c869, 2010. Disponível em: <https://doi.org/10.1136/bmj.c869>

MOORE, G. et al. Population Health Intervention Research: The Place of Theories. Trials, [s. 1.], v. 20, n. 1, p. 285, 2019. Disponível em: <https://doi.org/10.1186/s13063-019-3383-7>

PAIVIO, A. Dual Coding Theory: Retrospect and Current Status. Canadian Journal of Psychology, [s. 1.], v. 45, n. 3, p. 255-287, 1991. Disponível em: <https://doi.org/10.1037/ h0084295>

PEARL, J.; MACKENZIE, D. The Book of Why: The New Science of Cause and Effect. First editioned. New York: Basic Books, 2018.

PENA, S. B. et al. Medo de Cair e o Risco de Queda: Revisão Sistemática e Metanálise. Acta Paulista de Enfermagem, [s. 1.], v. 32, n. 4, p. 456-463, 2019. Disponível em: <https://doi. org/10.1590/1982-0194201900062>

ROCCO, T. S.; PLAKHOTNIK, M. S. Literature Reviews, Conceptual Frameworks, and Theoretical Frameworks: Terms, Functions, and Distinctions. Human Resource Development Review, [s. 1.], v. 8, n. 1, p. 120-130, 2009. Disponível em: <https://doi. org/10.1177/1534484309332617>

ROTHER, E. T. Revisão Sistemática x Revisão Narrativa. Acta Paul Enferm, [s. 1.], v. 20, p. vi, 2007.

SHEA, B. J. et al. AMSTAR 2: A Critical Appraisal Tool for Systematic Reviews that Include Randomised or Non-randomised Studies of Healthcare Interventions, or Both. BMJ, [s. 1.], v. 358, p. j4008, 2017. Disponível em: <https://doi.org/10.1136/bmj.j4008>

SOUZA FILHO, B. A. B. de; STRUCHINER, C. J. Uma Proposta Teórico-Metodológica para Elaboração de Modelos Teóricos. Cadernos Saúde Coletiva, [s. 1.], p. Ahead of Print, 2021. Disponível em: <https://doi.org/10.1590/1414-462X202129010180>

STERNE, J. A. C. et al. RoB 2: A Revised Tool for Assessing Risk of Bias in Randomised Trials. BMJ, [s. 1.], v. 366, p. 14898, 2019. Disponível em: <https://doi.org/10.1136/bmj.14898> ROBINS-I: A Tool for Assessing Risk of Bias in Non-Randomised Studies of Interventions. BMJ, [s. 1.], v. 355, p. i4919, 2016. Disponível em: <https://doi.org/10.1136/ bmj.i4919> 
VANDENBROUCKE, J. P. et al. Strengthening the Reporting of Observational Studies in Epidemiology (STROBE): Explanation and Elaboration. PLoS Medicine, [s. 1.], v. 4, n. 10, p. e297, 2007. Disponível em: <https://doi.org/10.1371/journal.pmed. 0040297>

VEKIRI, I. What Is the Value of Graphical Displays in Learning? Educational Psychology Review, [s. 1.], v. 14, n. 3, p. 261-312, 2002.

WESTREICH, D.; GREENLAND, S. The Table 2 Fallacy: Presenting and Interpreting Confounder and Modifier Coefficients. American Journal of Epidemiology, [s. 1.], v. 177, n. 4, p. 292-298, 2013. Disponível em: <https://doi.org/10.1093/aje/kws412>

\section{Note}

${ }^{1}$ B. A. B. de Souza Filho, E. F. Tritany and C. J. Struchiner were equally responsible for the conception; methodological choice; data analysis and interpretation; writing of the article and final review. This work is the result of the doctoral dissertation of the first author. There was no conflict of interest. 


\section{Resumo}

\section{Checklist para Relato Teórico em Estudos Epidemiológicos (CRT-EE): explicação e elaboração}

Introdução: A teoria é considerada imprescindível à pesquisa, mas muitas vezes tem seu valor subestimado no desenvolvimento e/ou relato em estudos epidemiológicos. Objetivo: Apresentar documento de elaboração e explicação de um instrumento para relato teórico em estudos epidemiológicos. Métodos: Foi desenvolvido um modelo teórico, baseado na teoria da Aprendizagem Significativa e revisão de literatura, para elencar dimensóes e variáveis relacionadas à qualidade de relato teórico. A revisão foi realizada entre julho de 2018 a agosto de 2019, nas bases de dados Medline, SciELO, LILACS, SCOPUS e Web of Science.

Não houve restrições relacionadas ao período das publicaçôes. Os idiomas utilizados foram: português, inglês e espanhol. Resultados: Foi desenvolvida uma lista de verificação de 15 itens, relacionados ao título (1 item), resumo (1 item), introdução (4 itens), métodos (4 itens), resultados (2 itens), discussão (2 itens) e conclusão (1 item) dos artigos; e apresentada uma coluna para marcação das informações solicitadas no artigo para cada item. Explicaçôes sobre cada item do instrumento são apresentadas, incluindo exemplos, referências a estudos e justificativas. Conclusáo: Este documento fornece orientaçóes para aprimorar o relato teórico em pesquisas epidemiológicas e facilita a avaliação teórica e interpretação dos estudos por revisores, editores e leitores.

> Palavras-chave: modelos teóricos; lista de checagem; estudos epidemiológicos. 


\section{ERRATUM}

In the article "Checklist for Theoretical Report inEpidemiological Studies (CRTEE): explanation and elaboration", with DOI number: http://dx.doi.org/10.1590/ S0103-73312021310124 published in the journal Physis: Revista de Saúde Coletiva, v. 31, n. 1, e310124, the Supplementary File was missing on page 28. 


\section{SUPPLEMENTARY FILE}

\section{(Table of References and Examples of Excerpts from Articles Used)}

Table 1. Main guiding studies for the theoretical foundation of the instrument.

\begin{tabular}{|c|c|c|}
\hline Theoretical Foundation Articles & Authors & Year \\
\hline $\begin{array}{l}\text { Uso de Teorías y Modelos en Artículos de una Revista } \\
\text { Latinoamericana de Salud Pública, 2000-2004. }\end{array}$ & Cabrera Arana GA & 2007 \\
\hline $\begin{array}{l}\text { Base Teórica en una Muestra de Investigaciones de la Facultad } \\
\text { Nacional de Salud Pública-Universidad de Antioquia, Colombia } \\
\text { 1965-2004. }\end{array}$ & $\begin{array}{l}\text { Cabrera Arana G, } \\
\text { Molina Marín G, } \\
\text { Rodríguez Tejada C. }\end{array}$ & 2005 \\
\hline $\begin{array}{l}\text { A Systematic Review of the Use of Theory in the Design of } \\
\text { Guideline Dissemination and Implementation Strategies and } \\
\text { Interpretation of the Results of Rigorous Evaluations. }\end{array}$ & $\begin{array}{l}\text { Davies P, Walker AE, } \\
\text { Grimshaw JM. }\end{array}$ & 2010 \\
\hline $\begin{array}{l}\text { Use of Theoretical Frameworks as a Pragmatic Guide for Mixed } \\
\text { Methods Studies: A Methodological Necessity? }\end{array}$ & $\begin{array}{l}\text { Evans BC, Coon DW, } \\
\text { Ume E. }\end{array}$ & 2011 \\
\hline $\begin{array}{l}\text { Understanding, Selecting, and Integrating a Theoretical Framework } \\
\text { in Dissertation Research: Creating the Blueprint for Your "House" }\end{array}$ & Grant C, Osanloo A. & 2014 \\
\hline Integration of a Theoretical Framework into your Research Study. & Heale R, Noble H. & 2019 \\
\hline $\begin{array}{l}\text { Is There a Conceptual Difference between Theoretical and } \\
\text { Conceptual Frameworks? }\end{array}$ & Imenda $S$. & 2014 \\
\hline $\begin{array}{l}\text { The PRISMA Statement for Reporting Systematic Reviews and } \\
\text { Meta-Analyses of Studies That Evaluate Health Care Interventions: } \\
\text { Explanation and Elaboration. }\end{array}$ & $\begin{array}{l}\text { Liberati A, Altman } \\
\text { DG, Tetzlaff J, et al. }\end{array}$ & 2009 \\
\hline $\begin{array}{l}\text { CONSORT } 2010 \text { Explanation and Elaboration: Updated Guidelines } \\
\text { for Reporting Parallel Group Randomised Trials. }\end{array}$ & $\begin{array}{l}\text { Moher D, Hopewell S, } \\
\text { Schulz KF, et al. }\end{array}$ & 2010 \\
\hline $\begin{array}{l}\text { Uma Proposta Teórico-Metodológica para Elaboração de Modelos } \\
\text { Teóricos. }\end{array}$ & $\begin{array}{l}\text { Souza Filho, BAB; } \\
\text { Struchiner, CJ. }\end{array}$ & 2021 \\
\hline $\begin{array}{l}\text { Strengthening the Reporting of Observational Studies in } \\
\text { Epidemiology (STROBE): Explanation and Elaboration. }\end{array}$ & $\begin{array}{l}\text { Vandenbroucke JP, } \\
\text { Poole C, Schlesselman } \\
\text { JJ, Egger M. }\end{array}$ & 2007 \\
\hline What Is the Value of Graphical Displays in Learning? & Vekiri I. & 2002 \\
\hline Dual Coding Theory: Retrospect and Current Status. & Paivo A. & 1991 \\
\hline $\begin{array}{l}\text { Theoretical and Conceptual Framework: Mandatory Ingredients of } \\
\text { a Quality Research. }\end{array}$ & $\begin{array}{l}\text { Adom D, Hussein EK, } \\
\text { Agyem JA. }\end{array}$ & 2018 \\
\hline
\end{tabular}

to be continued... 


\begin{tabular}{|l|l|l|}
\hline Theoretical Foundation Articles & Authors & Year \\
\hline $\begin{array}{l}\text { A History of the Evolution of Guidelines for Reporting Medical } \\
\text { Research: The Long Road to the EQUATOR Network. }\end{array}$ & Altman DG, Simera I. & 2016 \\
\hline $\begin{array}{l}\text { Literature Reviews, Conceptual Frameworks, and Theoretical } \\
\text { Frameworks: Terms, Functions, and Distinctions. }\end{array}$ & $\begin{array}{l}\text { Rocco TS, Plakhotnik } \\
\text { MS. }\end{array}$ & 2009 \\
\hline Teoria e Realidade. & Bunge M. & 1974 \\
\hline $\begin{array}{l}\text { Las Teorías y Modelos en la Explicación Científica: Implicancias } \\
\text { para la Enseńanza de las Ciencias. }\end{array}$ & Concari SB. & 2001 \\
\hline $\begin{array}{l}\text { Use of Theoretical and Conceptual Frameworks in Qualitative } \\
\text { Research. }\end{array}$ & Green HE. & 2014 \\
\hline The Theory Underlying Concept Maps and How to Construct Them. & Novak JD, Cañas AJ. & 2006 \\
\hline $\begin{array}{l}\text { The Origins of the Concept Mapping Tool and the Continuing } \\
\text { Evolution of the Tool. }\end{array}$ & Novak JD, Canãs AJ. & 2006 \\
\hline $\begin{array}{l}\text { Learning, Creating, and Using Knowledge: Concept Maps as } \\
\text { Facilitative Tools in Schools and Corporations. }\end{array}$ & Novak JD. & 1998 \\
\hline $\begin{array}{l}\text { The Promise of New Ideas and New Technology for Improving } \\
\text { Teaching and Learning. }\end{array}$ & Novak JD. & 2003 \\
\hline Aquisiçáo e Retençáo de Conhecimentos: Uma Perspectiva Cognitiva. & Ausubel DP. & 2000 \\
\hline A Subsumption Theory of Meaningful Verbal Learning and Retention. & Ausubel DP. & 1962 \\
\hline What's the Use of Theory? & van M, Catherine HA. & 1992 \\
\hline The Book of Why: The New Science of Cause and Effect. & Pearl J, Mackenzie D. & 2018 \\
\hline
\end{tabular}

Source: Prepared by the authors (2020).

\section{Examples of Excerpts from Published Articles for Each Item}

\section{Item 1: Title}

Did the article title mention the Theory/Theoretical Model and the related main variables that underlie the research?

\section{Example 1:}

"Lack of access to information on oral health problems among adults: an approach based on the theoretical model for literacy in health" 1 . 


\section{Example 2:}

"Effect of the Intervention Based on New Communication Technologies and the SocialCognitive Theory on the Weight Control of the Employees with Overweight and Obesity"2.

\section{Example 3:}

"The effect of counseling based on Bandura's self-efficacy theory on sexual self-efficacy and quality of sexual life" 3 .

\section{Item 2: Reasoned Abstract}

Did the article present, in the abstract, the Theory/Theoretical Model and its main related variables that underlie the research and explain how they were evaluated and what the main findings, potential limitations, and conclusions are, in relation to the Theory/Theoretical Model used?

\section{Example:}

"Background: Childhood obesity has become a global epidemic and physical inactivity and considered as one of the most important contributing factors. We aimed to evaluate a school-based physical activity intervention using social cognitive theory (SCT) to increase physical activity behavior in order to prevent obesity among overweight and obese adolescent girls.

Study Design: Randomized controlled trial study.

Methods: A seven-month randomized controlled trial based on SCT was implemented with 172 overweight and obese girl students (87 in intervention and 85 in control group), with the presence of their parents and teachers. Activities of the trial included: Sports workshops, physical-activity consulting private sessions, free practical and competitive sports sessions, family exercise sessions, text messages, and newsletters. Body Mass Index (BMI) and Waist Circumference (WC) were measured and questionnaires about duration of physical activity, duration of screen time (watching television and playing computer games) and psychological variables regarding the SCT constructs were obtained.

Results: Duration of physical activity (in minutes) and most of psychological variables (self-efficacy, social support, and intention) significantly increased at post-intervention, while hours of watching television and playing computer were significantly decreased $(P<0.001)$. The subjects' mean BMI and WC reduced in the intervention group from 
$29.47(4.05) \mathrm{kg} / \mathrm{m} 2$ to $28.5(4.35) \mathrm{kg} / \mathrm{m} 2$ and $89.65(8.15) \mathrm{cm}$ to $86.54(9.76) \mathrm{cm}$, although they were not statistically significant compared with the control group $(P=0.127$ and $P=0.504$, respectively).

Conclusions: School-based intervention using SCT led to an increase in the duration of physical activity and reduction in the duration of screen time in overweight and obese adolescent girls." ${ }^{4}$.

\section{Item 3: Mention and Refer}

Did the article explicitly mention and referenced to one or more Theories/ Theoretical Models on which the study is based? (In cases the study is based on a theoretical model specifically developed for the research, the authors must explicitly mention it and, whenever possible, provide a reference.)

\section{Example 1:}

"...Thus, based on the Transtheoretical Model TTM and a needs assessment of children and their parents, an intervention incorporating tailored exercise counseling combined with music skipping rope exercise was developed and administered to overweightlobese school-age children. The current study was designed to evaluate the long-term effects of the intervention using multiple dimensions of indicators to measure program outcomes..." 5 .

\section{Example 2:}

"...The aim of our study was to examine the effects of eight sessions of TTM-based tailored exercise counseling offered with music skipping rope exercise classes in modifying stages of change, decisional balance, self-efficacy, and BMI, whether it would improve the gluclose tolerance and lipid profile of overweight and obese school-age children." 5

\section{Item 4: Describe the Variables}

Did the article describe the variables of the Theory/Theoretical Model and their interrelations with the research cohesively and coherently?

\section{Example:}

"...Self-Determination Theory (SDT) is a comprehensive theory of behavioral motivation, which has proven to be particularly useful in the context of Physical Activity (PA) research, both for accounting for patterns of PA behavior and for informing the development 
of interventions for promoting PA. Central to this theory is the difference between autonomous and controlled motivation. Both autonomous and controlled motivation influence behavior, but they each lead to a different outcome, with autonomous motivation leading to greater commitment and long-standing maintenance of behavior. SDT posits that individuals are more likely to exhibit autonomous motivation when three basic psychological needs are supported: autonomy (i.e. the need to feel that one can choose one's behaviors), competence (the need to feel competent and confident) and relatedness (the need to feel connected to and understood by others). Motivational interviewing (MI) is defined as "a collaborative conversation style for strengthening a person's own motivation and commitment to change". Several researchers have argued that the specific client-centered communication skills used in Motivational Interviewing (MI) can be used to support client's basic psychological needs.

In recent years, numerous $P A$ counseling interventions that combine the theoretical framework of SDT with the practical strategies from MI have been developed and evaluated in randomized controlled trials. In general, these interventions are effective in promoting a sustained increase in $P A$. As discussed above, however, face-to-face PA counseling interventions are often too expensive to be implemented on a large scale. Webbased computer tailored PA interventions grounded in SDT and using the communication style and principles from MI, may be promising for promoting sustained PA behavior on the population level at relatively low costs. To our knowledge, however, no studies have yet evaluated the long term effects of SDT and MI in web-based PA promotion..." ${ }^{6}$.

\section{Item 5: Review Literature}

Did the article report the existence/absence of other Theories/Theoretical Models related to the analyzed phenomenon and explain the choice with scientific coherence?

\section{Example:}

"...To date, web-based computer tailored Physical Activity (PA) interventions have typically been based on traditional health behavior theories such as Social Cognitive Theory (SCT), Relf-Regulation Theory (SRT), the Trans-Theoretical Model (TTM) and the Theory of Planned Behavior (TPB). Interventions of this type, hereafter referred to as 'traditional interventions', make use of theoretical constructs such as stages of change, 
modeling, attitude and self-efficacy. Recent research on determinants of sustained PA behavior, however, shows another theoretical construct to be essential: autonomous motivation. Substantial evidence suggests that having higher autonomous motivation makes an individual more likely to persist with a PA routine. Although the concept of autonomous motivation does not feature explicitly in SCT, SRT, TTM or TPB, it is central to Self-Determination Theory (SDT) and Motivational Interviewing (MI). Applying the principles of SDT and MI in web-based computer-tailored PA interventions could be a promising improvement for these interventions, and could possibly be more effective in promoting sustained PA behavior than traditional web-based computer tailored PA interventions..." 6

\section{Item 6: Innovation/Theoretical Gap}

Did the article report the contribution of the chosen Theory/Theoretical Model to the phenomenon studied?

\section{Example:}

"... Based on these studies, it can be inferred that BIS is related to negative emotions and $B A S$ to positive emotions. Similarly, the anger response in an anger-inducing situation might be positively related with BAS and novelty seeking, but negatively related with BIS and harm avoidance. However, there are few studies on the relationship between anger response, BAS factors, and the four dimensions of temperament in the Psychobiological Model of Temperament and Character. Furthermore, despite the high likelihood of a similarity between the temperaments suggested by the Reinforcement Sensitivity Theory and Psychobiological Model of Temperament and Character, there is little research comparing the associations between each dimension or system and the anger response..." 7.

“...Thus, this study aimed to 1) examine the strength of associations between temperament factors and anger response among prisoners, 2) investigate the similarities and differences of each temperament measure from Gray's Reinforcement Sensitivity Theory and Cloninger's Psychobiological Model of Temperament and Character, and 3) explore the relationship between the temperament factors in each model to understand the nature of temperaments..."7. 


\section{Item 7: Explanatory Topic}

Did the article dedicate a topic (preferably at the beginning of the Methods session) to describe in depth how the Theory/Theoretical Model guided the methodological paths developed in the research?

\section{Example 1:}

\section{“...Theoretical framework}

...The Theory of Planned Behavior (TPB) model included two indicators of prescribing practice: percentage of prescriptions containing antibiotics and percentage of prescriptions containing two or more antibiotics. The two indicators were proposed by the World Health Organization (WHO) for measuring the rational use of medicines. Attitudes, subjective norms and perceived behavioral control in relation to antibiotic use were linked with intentions to prescribe antibiotics. They were deemed to be key factors shaping prescribing practice.

The TPB model assumed that antibiotic prescribing practice is influenced by behavioral intentions and the perceived behavioral control of the prescribers, with the former serving as a motivational factor while the latter reflecting the ability of the prescribers to fulfill their intentions. Attitudes, subjective norms and perceived behavioral controls are linked to each other and they can influence the behavioral intentions of the prescribers..." 8 .

\section{Item 8: Graphic Representation}

Did the article represented the Theory/Theoretical Model using a graph? (e.g.,. figure in the form of a concept map, causal diagram, among other forms). When it is not available in the article, did the article inform where and how it can be accessed (e.g., email address, appendix, supplementary file)?

\section{Example 1:}

“...Para se investigar os fatores associados à falta de acesso à informação em saúde bucal, utilizou-se como referencial teórico o Modelo de Alfabetização em saúde proposto por Sørensen et al., em 2012 (Figura). 
Modelo teórico da Alfabetização em saúde apresentado por Sørensen et al. em 2012.

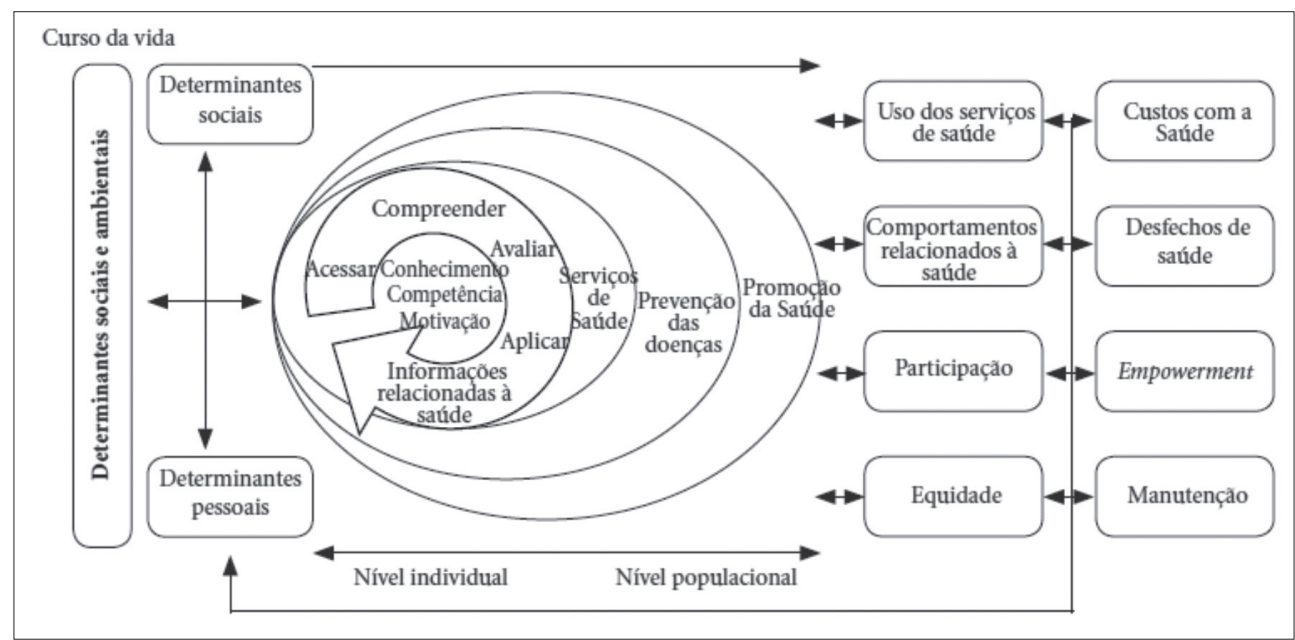

$O$ modelo exibe fatores proximais e distais determinantes elou determinados pela Alfabetização em saúde de forma dinâmica. Entre os distais, têm-se os fatores sociais e ambientais. Entre os determinantes proximais, têm-se os determinantes sociais situacionais e os pessoais. Outros fatores relacionados à Alfabetização em saúde (determinantes elou determinados) também apresentados no Modelo são: uso dos serviços de saúde, custos com a saúde, comportamentos relacionados à saúde, desfechos de saúde, participação das pessoas, empowerment, equidade e manutenção. Assim, o modelo adotado prevê o acesso a informaçôes como condição indispensável para aumentar os níveis de Alfabetização em saúde das pessoas..." 1 .

\section{Example 2:}

"...The theoretical framework was adapted from the Theory of Planned Behavior (TPB) model (Fig.). 


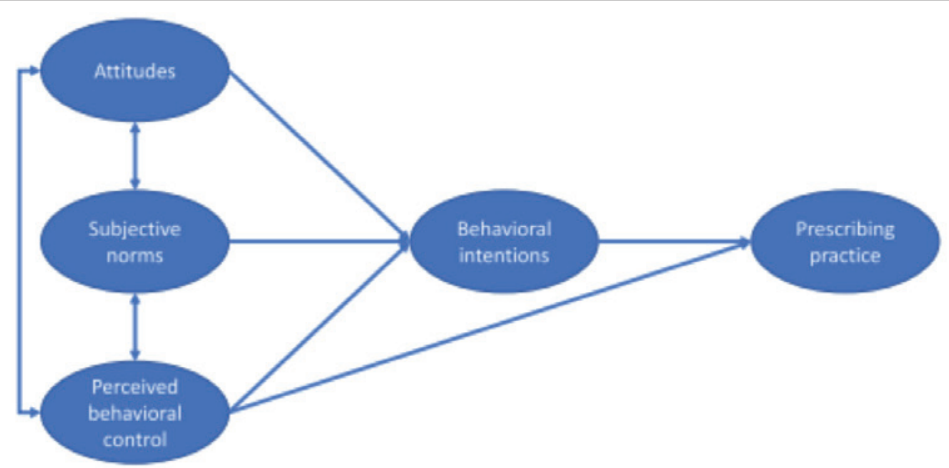

Fig. 1 The TPB framework for antibiotic prescribing practice in primary care. Antibiotic prescribing practice is influenced by behavioral intentions and the perceived behavioral control of the prescribers based on the theory of planned behaviors, with the former serving as a motivational factor while the latter reflecting the ability of the prescribers to fulfill their intentions. Attitudes, subjective norms and perceived behavioral controls are linked to each other and they can influence the behavioral intentions of the prescribers

The TPB model assumed that antibiotic prescribing practice is influenced by behavioral intentions and the perceived behavioral control of the prescribers, with the former serving as a motivational factor while the latter reflecting the ability of the prescribers to fulfill their intentions. Attitudes, subjective norms and perceived behavioral controls are linked to each other and they can influence the behavioral intentions of the prescribers...".

\section{Item 9: Conceptualize and Categorize}

Did the article conceptualize, categorize, and inform how interrelated research variables in the Theory/Theoretical Model will be recorded and/or classified?

\section{Example:}

“...As variáveis independentes foram reunidas em quatro subgrupos selecionados a partir do Modelo Teórico de Sørensen et al., sendo:

Determinantes pessoais: sexo, idade, estado civil, cor da pele autodeclarada, escolaridade, renda per capita e situação de trabalho atual. As variáveis idade e escolaridade, embora coletadas de forma quantitativa discreta, foram analisadas de forma categórica. A renda per capita foi estimada a partir da renda familiar, dividida pelo número de residentes no domicílio e posteriormente dicotomizada (menor ou igual à $R \$ 400,00$ / acima de $R \$ 400,00)$. O salário minimo vigente à época da coleta de dados era de $R \$ 465,00$ ou US\$ 245.0..." 
It is important to consider that the study cited as an example of items 8 and 9, despite presenting the graphic representation of the theoretical model and the description of the conceptualization and categorization of the variables contained in the model, as presented in the excerpts from the previous examples, the authors did not incorporate, in the analyzes carried out in their article, the complexity of the theoretical model as suggested in this checklist.

\section{Item 10: Theoretical Analysis}

Does the data analysis plan include all the variables of the Theory/Theoretical Model related to research? If any variables have been excluded or included in the analysis, please justify.

\section{Example 1:}

"...We assessed the psychometric properties of all Theory of Planned Behavior (TPB) variables. First, we checked whether these variables contained only 1 dimension using exploratory factorial analyses. We used the Kaiser eigenvalue-greater-than-one rule and Cattell scree plot to determine the number of dimensions for each variable. Each dimension was considered as a variable in the next steps of our analyses. Second, we assessed the internal consistency of each dimension with Cronbach alpha coefficient. We retained only dimensions for which the Cronbach alpha coefficient was equal to or greater than $0.60 . . . "$.

\section{Example 2:}

"...Two sets of analyses were conducted. The analysis on the non-twin sample ( $n=$ $1255-296=959)$ tested the overall model, and the analysis on the twin sample ( $n$ = 148 pairs) estimated the influence of genes, shared environment, and individualspecific environment. Using the non-twin sample, Pearson correlation among all related variables was conducted to test our first hypothesis. Next, a Structural Equation Model (SEM) was established to test the second hypothesis on mediation and the third hypothesis on moderation. Then, using the twin sample, the ACE model was fitted to each variable. This method allows decomposition of the variance of each variable into additive genetic (A), shared environmental (C), and nonshared environmental (E) sources. A larger proportion of additive genetic and shared environmental variance indicates a need for 
co-twin control. Using stress as an example to illustrate the co-twin design, the average stress level of a twin pair Stresstwin was calculated, and then subtracted from the individual stress level to obtain the individual-specific stress level Stressself that cannot be explained by genetic or common familial factors. Then, the twin shared stress and the individual-specific stress were both used as predictors. Finally, a SEM was established to evaluate the overall fit of the moderated mediation model after controlling for the twin shared variance. The model with fit indices CFI $>0.9$ and RMSEA $<0.08$ is considered a good fit (Hu \& Bentler, 1999).

The SEM and ACE model were conducted using Onyx, a graphical interface for Structural Equation Modeling (von Oertzen, Brandmaier, \& Tsang, 2015). All other analyses including data screening, descriptive statistics, correlation, and co-twin design were implemented using $R$ ( $R$ Core Team, 2017)..."10.

\section{Item 11: Result of the Variables}

Did the article present the results of all the variables of the analyzed Theory/ Theoretical Model? If any variable has been occulted, please justify.

\section{Example 1:}

"...Patient characteristics included in the hypothesized theoretical model were refined by combining bivariate and multiple regression analyses (inclusion criterion set at $p$ $<$.20) with an evaluation of each characteristic's merit based on past research and theory. These criteria were chosen to retain as many patient characteristics as possible since they could be significant in the final analyses of theory testing. As a result, 2 (i.e., race and health insurance policy holder) of the 13 patient characteristics to the prediction of cancer-related fatigue (CRF) severity were eliminated. Similarly, two other patient characteristics (i.e., employment data and treatment information) to the prediction of CRF severity had some but not all variables eliminated (i.e., was on a temporary leave; radiation therapy; surgery prior groups don't know if I had surgery and response choice was not selected; surgery during group this response choice was not selected). Next, the exogenous-endogenous model was tested to examine the overall fit. While the solution converged, the fit of the model was not acceptable (X2 = 160.18; $p<.01 ; d f=50$; $R M S E A=.089$; lower bound 90\% CI =0.074; upper bound 90\% CI =0.10; $C F I=$ 0.92; GFI = 0.95; $A I C=482$ ). The model was improved by removing nonsignificant 
paths one at a time and by including paths that had not been taken into account in the first solution. Both removing and including paths were based on evaluation of parameter estimates, modification indexes, goodness-of-fit tests, and theoretical considerations..."

\section{Example 2:}

"...A SEM model was established to test the hypothesized structure among variables. Demographics were also controlled in this model. All observed variables were standardized in order to obtain standard path coefficients. The moderating effect of emotional and cognitive control was tested between perceived stress and general distress (H3a) and between general distress and sleep quality (H3b). However, the second moderating effect was not significant. Although the $\chi 2$ of this model was still significant, $\chi 2(d f=24)=$ $85.44, p<.05$, fit indices all indicated that the model fit the data well, $C F I=0.965$, $R M S E A=0.054$. Therefore, a moderated mediation model was supported, where the effect of perceived stress on sleep quality was mediated by general distress, and emotional/ cognitive control moderated the effect of stress on general distress. A higher level of perceived stress was associated with a higher level of general distress, which in turn was associated with poor sleep quality. A higher level of cognitive and emotional control weakened the association between perceived stress and general distress. In other words, for people with better control capabilities, perceived stress is less likely to link to distress and therefore may not lead to poor sleep quality..."10.

\section{Item 12: Theoretical Impact}

Did the article report how the study's findings impact the Theory/Theoretical Model and show it in the final Theory/Theoretical Model (in the same way as in item 8; for instance, figure in the form of concept map, causal diagram, among other forms)?

\section{Example:}

"...The direct and indirect paths in the final parsimonious theoretical model are shown in Figure, with the fitting measures indicating a good fit, improved over the original model $(X 2=17.76 ; p=.22 ; d f=14 ; R M S E A=.03$; lower bound $90 \%$ $C I=0.00$; upper bound 90\% $C I=.068 ; C F I=.99 ; G F I=0.99 ; A I C=79)$. The direct paths demonstrate the following for persons with cancer: younger age $(t=-2.18)$, greater number of comorbid conditions $(t=3.36)$, and being female $(t=2.11)$ predicts 
greater CRF severity. Having surgery anytime prior to chemotherapy $(t=-2.85)$ predicts greater average severity of the other symptoms. Contrary to expectations, the relationship between $C R F$ severity and average symptom severity was not reciprocal. Instead, greater $C R F$ severity predicts greater average symptom severity $(t=9.69)$. The effect of $C R F$ severity on the average symptom severity was found to be significant $(t=2.07)$, but the reverse effect was not significant $(t=1.16)$. Correspondingly, the model fitting measures indicated that when eliminating the effect of the average symptom severity on CRF severity while retaining the effect of $C R F$ severity on the average symptom severity, the model fit was improved..." ${ }^{11}$.

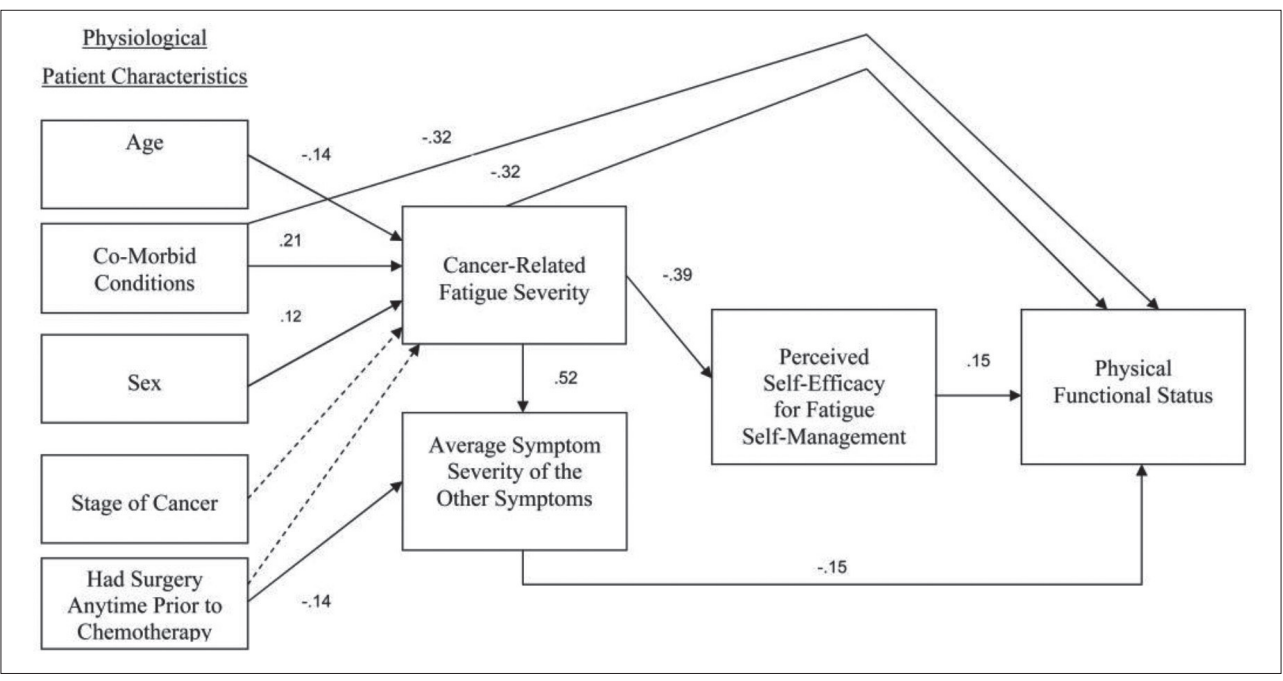

\section{Item 13: Discussion and Reflection}

Did the article discuss the study's findings cohesively and coherently based on the interrelations expected and those found using the Theory/Theoretical Model?

\section{Example 1:}

"...Three relevant findings can be drawn from the present study. First, a high proportion of people included in our analyses had good past and good future Noninsulin Antidiabetic Drug (NIAD) adherence. Second, past NIAD adherence was both a strong predictor and a modifying factor for the prediction of future NIAD adherence. Third, the Theory of Planned Behavior (TPB) was good at predicting intention to adhere to the NIAD in 
adults with type 2 diabetes, but not at predicting future NIAD adherence even after stratifying participants according to past adherence level. Moreover, the TPB better predicted both intention to adhere to the NIAD and future NIAD adherence in the past nonadherers group than the past adherers group. Thus, the TPB could be more effective in predicting the NIAD adherence of past nonadherers than that of past adherers..." .

\section{Example 2:}

"...The results of our study indicate that combined approach of TTM-based exercise counseling and exercise classes was more beneficial to overweightlobese children than exercise classes alone. In addition, development of the theory-based intervention incorporating information obtained from the needs assessment of children and parents increased the intervention effectiveness. The TTM has been criticized in that it does not appear to have long-term effects, and is difficult to apply to complex health behaviors such as physical activity [21]. However, demonstration of significant differences between the experimental and control groups in BMI and self-efficacy at posttest ( 6 months after the intervention) indicates that our study partially supports the effectiveness of the TTMbased exercise intervention..." 5 .

\section{Item 14: Limitations}

Did the article describe the limitations of the Theory/Theoretical Model (e.g., Theory/Theoretical Model simplified or incomplete and possible exclusions of variables in the analysis)?

\section{Example:}

"...There was little change in the physical activity (PA) mediators as a result of the intervention, which raises several issues. The mediators were assessed in relation to "regular PA", however the The Exercise and Nutrition Routine Improving Cancer Health (ENRICH) intervention specifically targeted walking and resistance training. The lack of specificity may have also been an issue in how the Social Cognitive Theory (SCT) constructs were defined. Self-efficacy was examined as one category, rather than breaking it down into the more specific constructs of task or barrier self-efficacy. There may have been cross-over or contamination between the individual construct measures, and it may be difficult to separate the individual effects of self-efficacy and outcome expectations. The measure used to assess goal setting in this analysis is a measure of 
likelihood of performing regular $P A$, which may be a measure of motivation or intention, and makes it difficult to tease out separate effects of these constructs..." ${ }^{12}$.

\section{Item 15: Conclusions}

Did the article present a general interpretation of the Theory/Theoretical Model used in the study considering other Theories/Theoretical Models regarding potentialities, gaps, and implications for future studies on this Theory/Theoretical Model?

\section{Example 1:}

"...The present study suggests that the Theory of Planned Behavior (TPB) is a good tool to predict intention to adhere and future Noninsulin Antidiabetic Drug (NIAD) adherence, particularly in past NIAD nonadherers. Our results could have implications for clinical practices and research. This study helps health professionals (physicians, pharmacists, nurses, and health educators) and researchers understand the adoption of NIAD adherence in adults with type 2 diabetes using the TPB. Health professionals and researchers should keep in mind that the past NIAD adherence level could influence the TPB's ability to predict NIAD adherence among adults with type 2 diabetes. Therefore, the content of future NIAD adherence-enhancing interventions based on TPB should be adapted according to investigators' aim to either improve or maintain the NIAD adherence of adults with type 2 diabetes. It is relevant to discriminate past adherers from past nonadherers when one wishes to implement NIAD adherence-enhancing interventions..." 9 .

\section{Example 2:}

"...The present study is the first to evaluate the Self-Determination Theory (SDT) and Motivational Interviewing (MI) in a web-based computer tailored physical activity (PA) intervention. In this study, I Move was effective in increasing weekly minutes of MVPA at 12 months from baseline, while the effect of Active Plus on this outcome disappeared. This finding provides support for the use of SDT and MI in web-based computer tailored PA interventions. However, Active Plus was found to be effective in increasing weekly days with $\geq 30 \mathrm{~min} P A$ at 12 months, while I Move was not. Together these results suggest that web-based computer tailored PA interventions might best include elements 
based on both SDTIMI and traditional health behavioral theories. To be more precise, it is arguable that the focus of the theoretical foundations, used in new web-based PA interventions should depend on the intended program outcome. If the intended program outcome is to get individuals to comply with PA guidelines, an emphasis on traditional health behavioral theories might be most suitable. If the intended program outcome is to increase overall PA behavior (without taking into account PA guidelines), making strong use of MI and SDT might be more appropriate. However, in order to draw firm conclusions, more research should be done on the effects of SDT and MI in web-based $P A$ promotion. Future research should also assess the working mechanism underpinning the long-term effects of this type of intervention, and whether or not these effects are mediated by an increase in autonomous motivation..." 6 .

\section{References}

1. Roberto LL, Noronha DD, Souza TO, et al. Falta de Acesso a Informaçôes Sobre Problemas Bucais entre Adultos: Abordagem Baseada no Modelo Teórico de Alfabetização em Saúde. Ciênc saúde coletiva. 2018;23(3):823-835. doi:10.1590/1413-81232018233.25472015

2. Abdi J, Eftekhar H, Mahmoodi M, Shojayzadeh D, Saber M. Effect of the Intervention Based on New Communication Technologies and the SocialCognitive Theory on the Weight Control of the Employees with Overweight and Obesity. Journal of Research in Health Sciences. 2015;15(4):256-261.

3. Alimohammadi L, Zarei F, Mirghafourvand M. The Effect of Counseling Based on Bandura's Self-Efficacy Theory on Sexual Self-Efficacy and Quality of Sexual Life. Women \& Health. Published online 2019:1-14. doi:10.1080/0363 0242.2019.1662871

4. Bagherniya M, Darani FM, Sharma M, et al. Assessment of the Efficacy of Physical Activity Level and Lifestyle Behavior Interventions Applying Social Cognitive Theory for Overweight and Obese Girl Adolescents. J Res Health Sci. 2018;18(2):e00409.

5. Ham OK, Sung KM, Lee BG, Choi HW, Im E-O. Transtheoretical Model Based Exercise Counseling Combined with Music Skipping Rope Exercise on Childhood Obesity. Asian Nursing Research. 2016;10(2):116-122. doi:10.1016/j. anr.2016.03.003 
6. Friederichs SA, Oenema A, Bolman C, Lechner L. Long Term Effects of SelfDetermination Theory and Motivational Interviewing in a Web-Based Physical Activity Intervention: Randomized Controlled Trial. Int J Behav Nutr Phys Act. 2015;12(1):101. doi:10.1186/s12966-015-0262-9

7. JangE. The Relation Between TemperamentandAngerResponseAmong Prisoners: Comparison of Reinforcement Sensitivity Theory and the Psychobiological Model of Temperament and Character. Heliyon. 2019;5(7):e02103. doi:10.1016/j. heliyon.2019.e02103

8. Liu C, Liu C, Wang D, Deng Z, Tang Y, Zhang X. Determinants of Antibiotic Prescribing Behaviors of Primary Care Physicians in Hubei of China: A Structural Equation Model Based on the Theory of Planned Behavior. Antimicrob Resist Infect Control. 2019;8(23):8. doi:10.1186/s13756-019-0478-6

9. Zomahoun HTV, Moisan J, Lauzier S, Guillaumie L, Grégoire J-P, Guénette L. Predicting Noninsulin Antidiabetic Drug Adherence Using a Theoretical Framework Based on the Theory of Planned Behavior in Adults With Type 2 Diabetes: A Prospective Study. Medicine. 2016;95(15):e2954. doi:10.1097/ MD.0000000000002954

10. Hu Y, Visser M, Kaiser S. Perceived Stress and Sleep Quality in Midlife and Later: Controlling for Genetic and Environmental Influences. Behavioral Sleep Medicine. 2020;18(4):537-549. doi:10.1080/15402002.2019.1629443

11. Hoffman AJ, von Eye A, Gift AG, Given BA, Given CW, Rothert M. Testing a Theoretical Model of Perceived Self-efficacy for Cancer-Related Fatigue Self-management and Optimal Physical Functional Status: Nursing Research. 2009;58(1):32-41. doi:10.1097/NNR.0b013e3181903d7b

12.Stacey FG, James EL, Chapman K, Lubans DR. Social Cognitive Theory Mediators of Physical Activity in a Lifestyle Program for Cancer Survivors and Carers: Findings from the ENRICH Randomized Controlled Trial. Int J Behav Nutr Phys Act. 2016;13(1):49. doi:10.1186/s12966-016-0372-z 